\title{
Influence of Geometrical Parameters on Performance of Grouted Mortise and Tenon Joints for Application in Prefabricated Underground Structures
}

\author{
Xiuren Yang $\mathbb{D},{ }^{1,2,3}$ Zhongheng Shi, ${ }^{1}$ and Fang Lin $\mathbb{D}^{2,3}$ \\ ${ }^{1}$ School of Civil Engineering, Beijing Jiaotong University, Beijing 100044, China \\ ${ }^{2}$ Beijing Urban Construction Design and Development Group Co., Ltd., Beijing 100037, China \\ ${ }^{3}$ National Engineering Laboratory for Green \& Safe Construction Technology in Urban Rail Transit, Beijing 100037, China
}

Correspondence should be addressed to Xiuren Yang; yangxr@bjucd.com and Fang Lin; felyo@foxmail.com

Received 9 February 2019; Revised 13 April 2019; Accepted 21 April 2019; Published 2 May 2019

Academic Editor: Hayri Baytan Ozmen

Copyright (c) 2019 Xiuren Yang et al. This is an open access article distributed under the Creative Commons Attribution License, which permits unrestricted use, distribution, and reproduction in any medium, provided the original work is properly cited.

Prefabricated underground structures were first researched in China to address the serious social and environmental issues associated with underground construction. Five metro stations have been built on Line 2 of the Changchun Metro in China using this new prefabrication technology. The joints connecting prefabricated elements are the most critical components in such prefabricated structures. In this study, experiments and numerical simulations investigating the influences of different grouted mortise and tenon joint geometrical parameters were conducted to determine the optimal parameters and ensure proper performance. To do so, a finite element model was built with the appropriate characteristics using the experimental results, and an analysis of the influence of different geometrical parameters was conducted. The results indicate that increasing the dip angle of the tenon could improve the flexural rigidity of the joint, but its effect was relatively small compared to that of the other parameters. Increasing the width of the tenon only had a positive effect on the flexural rigidity of the joint when the width was relatively small and under small axial loads. Increasing the length of the tenon helped to enhance the flexural performance of the joint; however, this advantage was not obvious when the tenon length was relatively long. Proper indentation of the joint improved the flexural capacity under a small axial load, but was not beneficial under a high axial load. The findings of this study are of value to help researchers and engineers more effectively design prefabricated underground structures.

\section{Introduction}

With the rapid development of rail transit construction in China, social awareness of impacts to environmental quality during metro construction has continuously increased. Furthermore, long and tight construction periods, large resource consumption, and a decrease in young laborers in civil engineering (and the accompanying shortage of skilled labor and decreased guarantee of structural quality) present significant challenges for traditional metro station construction methods. These situations are particularly prominent in cities in the northeast of China, such as Changchun city, where it gets so cold that a four- to five-month winter break is required during metro construction as it is difficult to guarantee construction quality at such low temperatures. This results in significant deadline pressure. To address these problems in cold regions, Yuanjiadian station on Line 2 of the Changchun Metro (shown in Figure 1) was selected in 2012 as a test section to conduct research on applications of prefabricated technology in underground engineering. To date, five prefabricated metro stations have been completed, and remarkable results have been achieved [1]. Using prefabricated structures, site assembly and construction can be conducted without the need for wet spraying of concrete and can accordingly reduce environmental pollution and resource consumption as well as address many construction problems faced during the winter in cold regions. In addition, the high degree of mechanization possible when installing prefabricated structures increases construction efficiency and accuracy, considerably reducing the construction period [2-4]. 


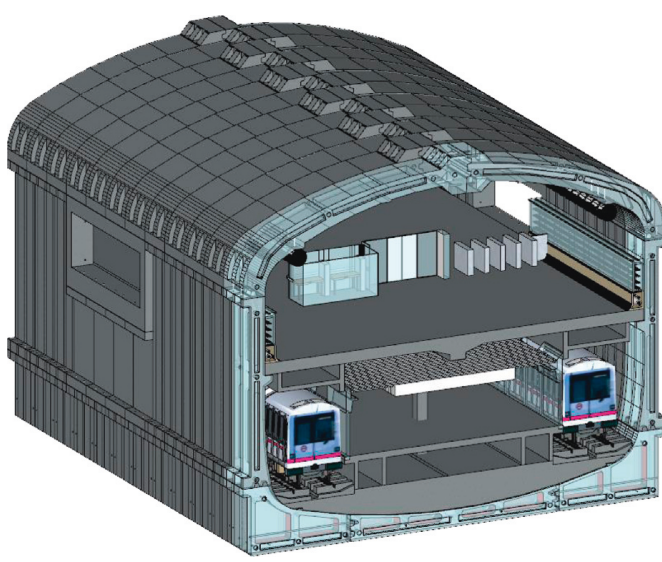

(a)

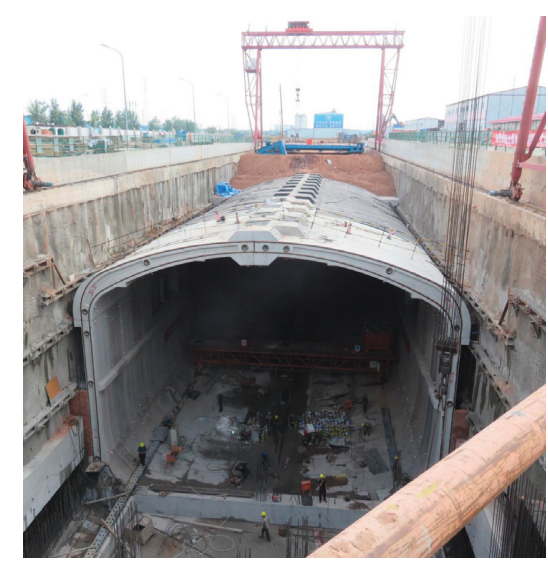

(b)

Figure 1: Metro station constructed of prefabricated components: (a) rendering and (b) picture.

For prefabricated above-ground buildings, the relevant technology and management systems have already been established as there has been a considerable increase in engineering applications of such structures in recent years [5-8]. The use of prefabrication technology in underground structures can be traced back to the 19th century, when prefabricated linings were first applied in shield tunnels with circular sections [9]. The former Soviet Union, Holland, France, Japan, and many other countries have all applied prefabrication technology to some aspect of metro construction [10]. However, the application range of these previously developed technologies has remained limited because of various technological limitations, including the required use of cast-in-place concrete to make the connection joints, which has been observed to create difficulties in waterproofing. To date, most prefabrication technologies have been mainly applied to simple structures with small cross sections such as metro tunnels and municipal pipelines $[11,12]$. There have been few studies on the application of prefabricated technology to large underground structures such as those used in the Changchun metro.

The joints connecting prefabricated elements have been recognized as the potentially weakest parts of a prefabricated structure, and the different geometric structures of different joints can affect their mechanical behavior. Therefore, in order to address the limitations of prefabricated technology in large underground applications, it is necessary to study the effects of the multiple geometrical parameters that define the joints between prefabricated components. In this study, experiments were conducted and used to optimize numerical simulations evaluating different geometrical joint parameters. Using the results of this comprehensive analysis of the influence of joint geometry on joint performance, we then provide guidance on selecting a reasonable and effective joint geometry.

\section{Project Overview}

The five metro stations built in Changchun using prefabricated structures are all cut-and-cover stations supported by anchor-pile systems. Each of these horseshoe- shaped two-story stations is $20.5 \mathrm{~m}$ wide and $17.45 \mathrm{~m}$ high. The station structures were built by assembling seven $2 \mathrm{~m}$ wide prefabricated components into the section geometry shown in Figure 2. The grouted mortise and tenon joint shown in Figure 3 (Chinese patent number: ZL201420165101.X) was applied between prefabricated components. The grouted segment, indicated by the blue shading in Figure 3, was designed to connect two prefabricated elements to restrict deformation between the mortise and the tenon and to limit the opening of the seam.

\section{Materials and Methods}

Four main geometrical parameters, the dip angle $(\alpha)$, width $(w)$, length $(l)$, and indentation ( $i)$, form the structure of a mortise and tenon joint, as defined in Figure 4. Figure 5 depicts the three-dimensional appearance of the indentation forming the joint. In this study, we conducted experiments and simulations to investigate the influences of the different geometrical parameters on the mechanical behavior of the joint, particularly its flexural bearing capacity. The experiments and simulations were designed to supplement one another, as the simulation model was optimized using the experimental results and the performance of the joint was analyzed using the results of both the experiments and simulations.

\section{Experimental Method}

Prototype experiments on a $1: 1$ scale loaded in the key working direction (the cross-sectional direction in Figure 2) were conducted to evaluate the influence of different tenon lengths on the performance of the joint. As depicted in Figure 6, $95 \mathrm{~mm}$ and $195 \mathrm{~mm}$ long joints used for circumferential and longitudinal connections, respectively, were chosen as the test specimens. The width of the test segments in the longitudinal direction was reduced from $2000 \mathrm{~mm}$ to $800 \mathrm{~mm}$ to accommodate the testing equipment. The dip angles and indentations of both types of specimen were set to $76^{\circ}$ and $0 \mathrm{~mm}$, respectively. 

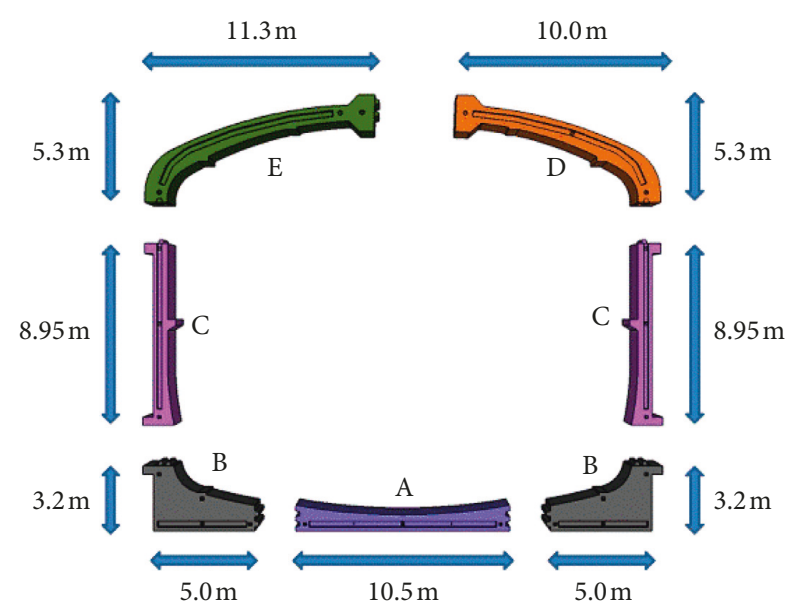

FIgURE 2: Geometry of a Changchun Line 2 station prefabricated element.

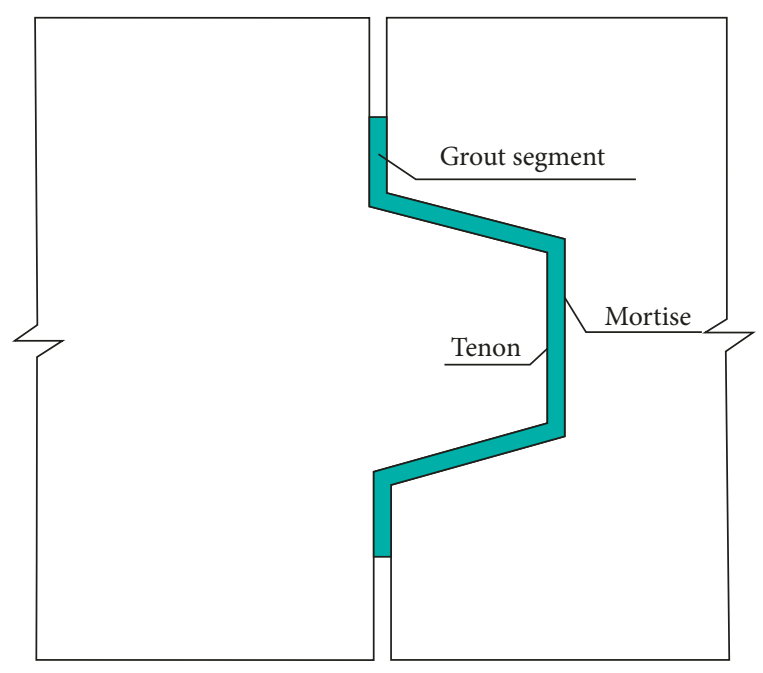

Figure 3: Grouted mortise and tenon joint.

Figure 7 shows the loading configuration used to test the specimens. The axial load $(N)$ and bending moment $\left(F_{M}\right)$ were controlled separately using two different jacks (shown in Figure 8). The two jacks were orthogonal: one jack applied a constant horizontal (axial) load $(N)$ to one side with the reaction force being supplied by a wall, while the other jack applied a vertical load $F$ to induce bending moment $\left(F_{M}\right)$ via a load distribution girder. The load $F$ was applied using displacement control at a rate of $\mathrm{mm}$. Four test cases were evaluated: one with an axial load $N=500 \mathrm{kN}$ grouted with a modified epoxy resin and three with an axial load of $N=1600 \mathrm{kN}$ grouted with a modified epoxy resin, a modified cement-based material, and no grout, as listed in Figure 7.

\section{Simulation Method}

5.1. Numerical Model. Numerical models the same size as the experimental specimens were built using finite element modeling (FEM). Because the geometrical parameters of the mortise and tenon joint were the key factors under investigation, the rebar and grouting segments were neglected in the model. As can be seen in Figure 9, the concrete structure of the main body was simulated using hexahedral solid elements, and the interface between the mortise and tenon parts was simulated as concrete-concrete contact. There were 69312 elements and 50626 nodes in the completed model.

5.2. Material Parameters. The density, modulus of elasticity, and Poisson's ratio of C50 concrete were used in the model, with values of $25 \mathrm{kN} / \mathrm{m}^{3}, 34.5 \times 10^{6} \mathrm{kN} / \mathrm{m}^{2}$, and 0.2 , respectively. The nonlinear Coulomb friction law was used to model the concrete-concrete contact with a normal stiffness modulus, shear stiffness modulus, cohesion, internal friction angle, and tensile strength of $34.5 \times 10^{6} \mathrm{kN} / \mathrm{m}^{3}$, $8 \times 10^{6} \mathrm{kN} / \mathrm{m}^{3}, 0 \mathrm{kN} / \mathrm{m}^{2}, 50^{\circ}$, and $0 \mathrm{kN} / \mathrm{m}^{2}$, respectively.

5.3. Boundary Conditions. Figure 10 shows the loads and boundary conditions applied in the numerical model. A pin support was defined on one end and a roller support was defined on the other, so no rotational restrictions were applied to either end. An area load $F_{N}$ was then applied to both sides while the bending moment was applied by a line load $F_{M}$ at the same locations as in the experiment.

5.4. Model Verification. Figures 11 and 12 present comparisons of the results obtained using the above numerical model and the experimental results under an axial load of $1600 \mathrm{kN}$ with the modified epoxy resin as a grouting material. The calculated values can be observed to be slightly higher than the experimental values, but the trends of the curves and their inflection points are nearly the same. Moreover, the differences between the model and the experiment decrease with applied loading. In summary, the calculated curve generally agrees with the experimental curve. Therefore, the parameters and boundary conditions of the numerical model were verified to be reasonable.

5.5. Simulation Cases. Based on the verified numerical model, an additional numerical model of larger size, shown in Figure 13, was built with the same materials and contact conditions to eliminate the deep-beam size effect of the model and focus on the joint structure. Accordingly, the length of the model specimen was extended from $2.7 \mathrm{~m}$ to $4 \mathrm{~m}$ (so that each part was $2 \mathrm{~m}$ long). Similarly, the width of the model specimen was increased from $800 \mathrm{~mm}$ to $1 \mathrm{~m}$ to provide more convenient data conversion for subsequent research and practical application. The loading line was located in the middle of each half of the specimen, $1 \mathrm{~m}$ from the ends, to ensure pure bending in the joint region.

Table 1 provides a list of simulation cases varying the four main mortise and tenon joint parameters under seven different axial loads. A $70-90^{\circ}$ range for the dip angle was investigated to maintain an effective shear key [13]. Six different joint widths were evaluated with the other parameters fixed to remove the influence of their variation, as 


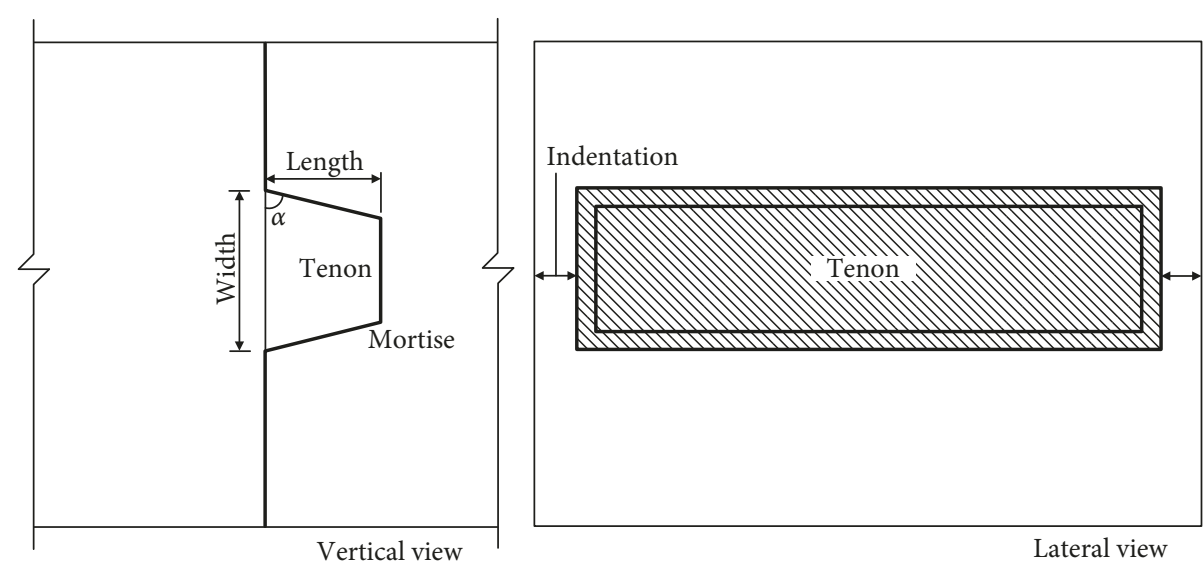

FIGURE 4: Geometric design of a mortise and tenon joint.

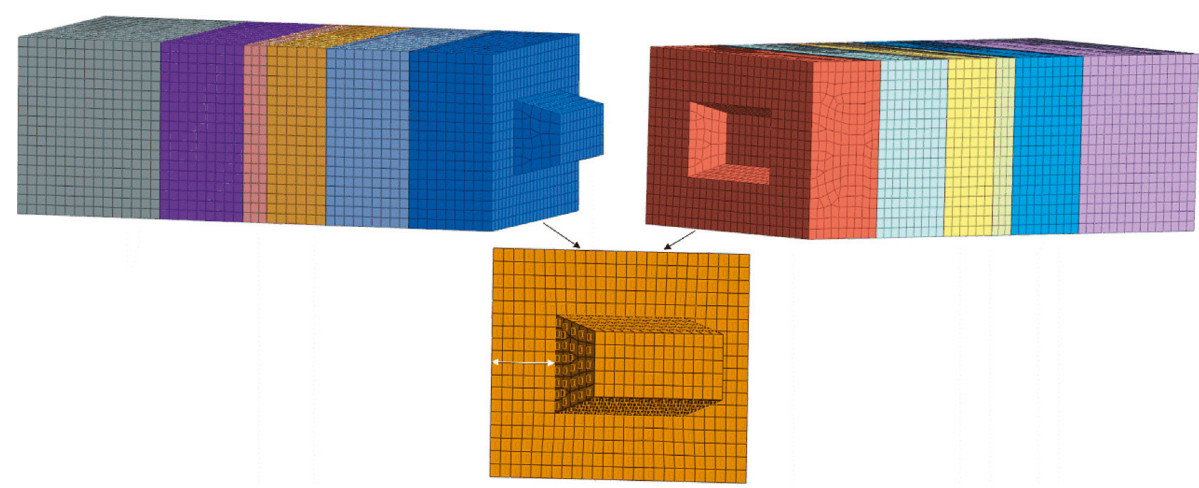

FIgURE 5: Three-dimensional sketch of the indentation of a mortise and tenon joint.
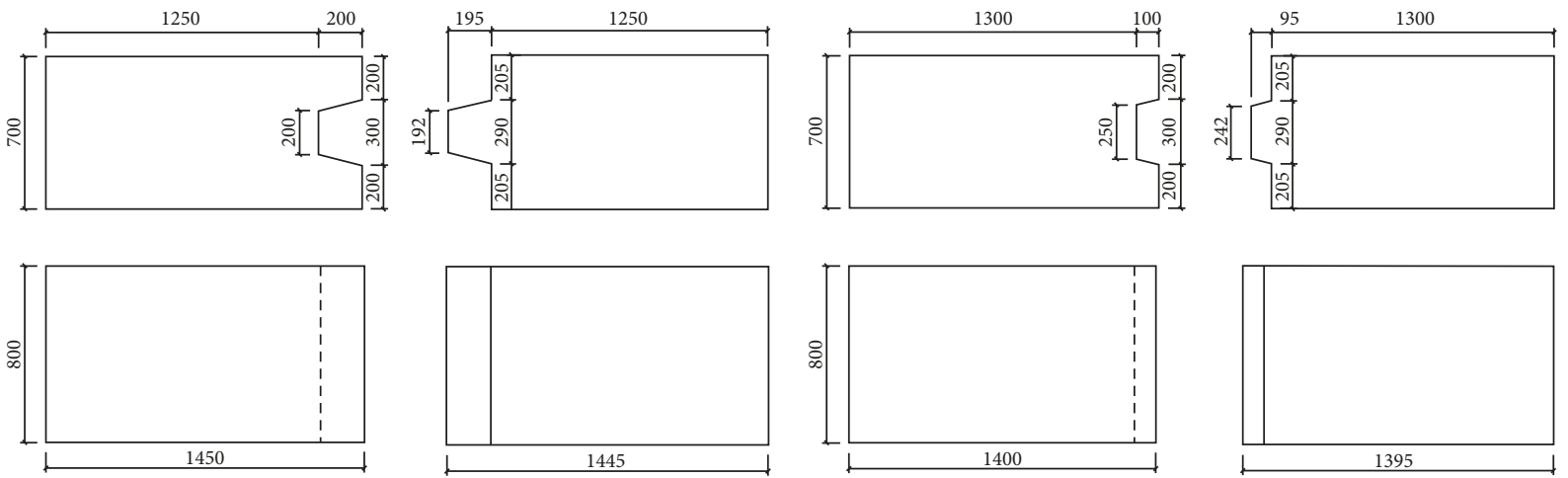

(a)

(b)

Figure 6: Plan and facade view of experimental specimens: (a) long joint and (b) short joint (all dimensions are in mm).

described in Table 1. Similarly, when evaluating the effect of the joint length parameter, the width was fixed at $300 \mathrm{~mm}$, the indentation was fixed at $0 \mathrm{~mm}$, and the dip angle was fixed at $90^{\circ}$, because except for the length, the other dimensions of the mortise and tenon joint will always be consistent when the dip angle is fixed at a right angle. Indentations of $0 \mathrm{~mm}, 150 \mathrm{~mm}, 200 \mathrm{~mm}$, and $250 \mathrm{~mm}$ were also evaluated, corresponding to indentation ratios of $0 \%$, $30 \%, 40 \%$, and $50 \%$, respectively, calculated as $2 i /$ width of the entire joint.

\section{Results and Discussion}

6.1. Influence of Different Dip Angles. Figure 14 shows the relationship between the bending moment $M$ and rotation angle $\theta$ for the different dip angles evaluated. At the beginning of loading, for all axial loads, the joint exhibits little rotation and high flexural rigidity, and the dip angle appears to have no influence. As the joint begins to rotate with applied moment and its flexural rigidity begins to decrease, there is still little difference in the curves for the various dip 


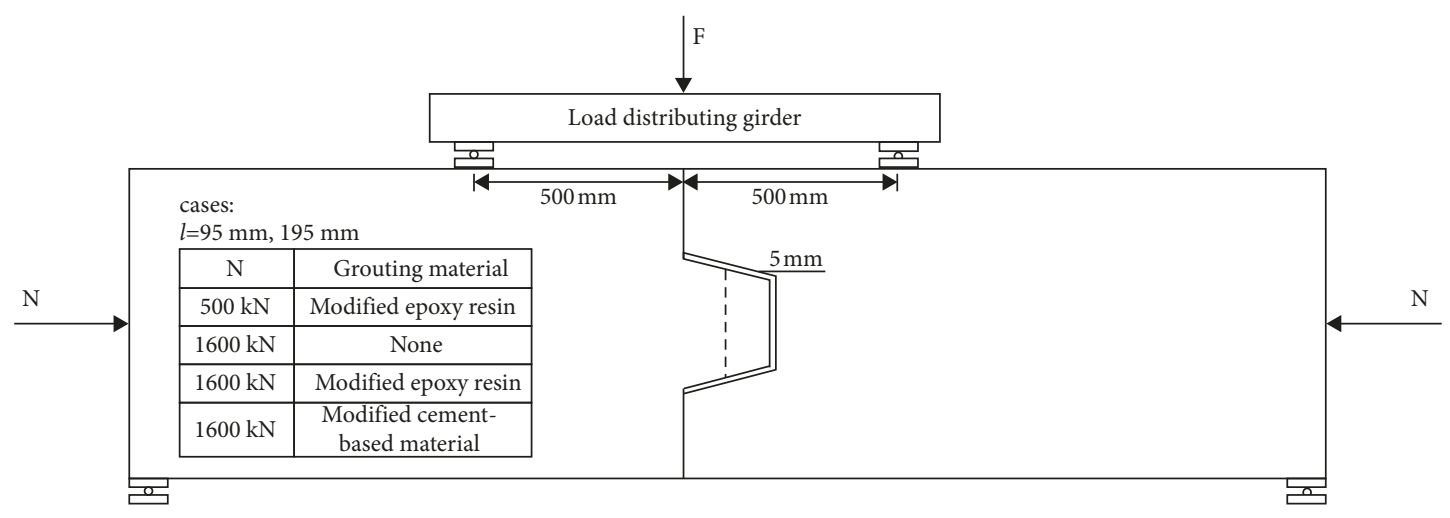

FIgURE 7: Loading configuration and cases.

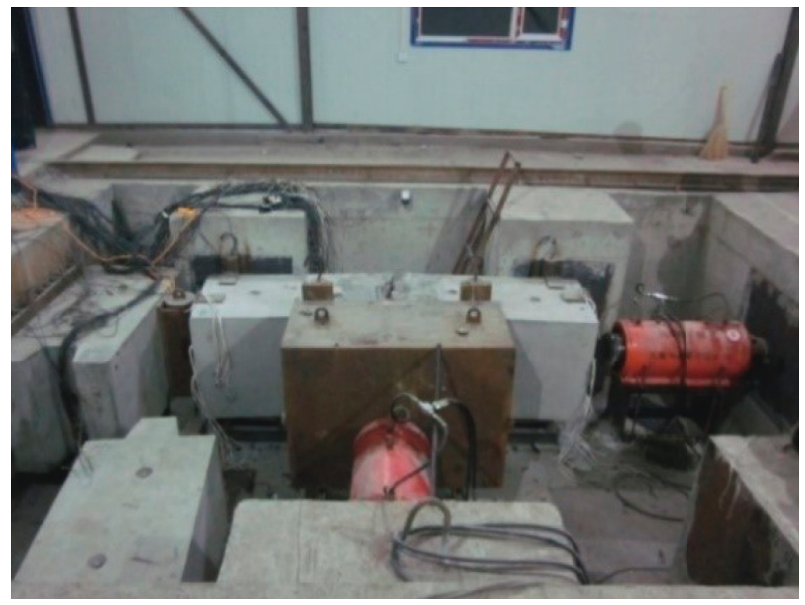

FigURE 8: Loading apparatus used for specimen tests.

angles, indicating that the dip angle has little effect on flexural rigidity at this stage. However, as the applied moment increases further, the rate of rotation increase begins to differentiate for different dip angles. Under the same bending moment, the flexural rigidity can be arranged in order of decreasing rigidity for dip angles of $90^{\circ}>80^{\circ}>76^{\circ}>70^{\circ}$ under small axial loads $(\leq 1000 \mathrm{kN})$. Note that this order changes under higher axial loads, in which case the $80^{\circ}$ dip angle exhibits the largest flexural rigidity. In summary, the effect of different dip angles on the flexural rigidity of the joint reduces as the axial load increases, to a point. Notably, the curves of the four dip angles nearly coincide under an axial load of $4000 \mathrm{kN}$, which indicates that the flexural rigidity under different dip angles is nearly the same at a sufficiently high axial load.

Overall, increasing the dip angle within a reasonable limit can improve the flexural rigidity of the joint in the nonlinear stage, but the increase in flexural rigidity slows as the axial load increases. When the axial load is sufficiently high, there is little difference in flexural rigidity under any dip angle. It was also observed that, for the joint with the $90^{\circ}$ dip angle, the stress component in the axial load direction increased significantly as there was greater stress concentration at the top of the tenon when the applied axial load was very large; this reduces the carrying capacity of the tenon in the later periods of loading. Therefore, all factors should be comprehensively considered when selecting the dip angle of the tenon for prefabricated structures used to construct metro stations.

6.2. Influence of Different Tenon Widths. Figure 15 displays the relationship between the bending moment $M$ and rotation angle $\theta$ for different tenon widths under various axial loads. All curves are nearly coincident in the linear stage under any axial load, indicating that the width of the tenon has little effect on the mechanical behavior of the joint in the beginning. With increased bending moment, the joints of different widths begin to rotate and the flexural rigidity starts to decline, but there is still considerable overlapping of the different curves corresponding to the different widths, indicating that the tenon widths have little effect on flexural rigidity at this stage. When the bending moment increases to a sufficiently high value, the flexural rigidities of the joints with tenon widths between $200 \mathrm{~mm}$ and $350 \mathrm{~mm}$ are larger than those of the joints with tenon widths of $400 \mathrm{~mm}$ and $450 \mathrm{~mm}$ under a small axial load $(500 \mathrm{kN})$. This difference decreases as the axial load increases. Indeed, the curves for all tenon widths are almost the same when the axial load is in the range of $1500-3000 \mathrm{kN}$. However, when the axial load reaches $4000 \mathrm{kN}$, the flexural rigidities for widths between $200 \mathrm{~mm}$ and $350 \mathrm{~mm}$ are slightly larger than those for $400 \mathrm{~mm}$ and $450 \mathrm{~mm}$ widths. In general, increasing the width of the tenon can improve the flexural rigidity when the width of tenon is relatively small $(200-350 \mathrm{~mm})$. However, this might not have a positive effect on the flexural rigidity when the width of tenon is relatively large $(400 \mathrm{~mm}$ or $450 \mathrm{~mm}$ ).

Overall, increasing the width of the tenon only has a positive effect on flexural rigidity when the width is relatively small and under small axial load.

6.3. Influence of Different Tenon Lengths. Figure 16 shows the crack development in $195 \mathrm{~mm}$ and $95 \mathrm{~mm}$ long tenons under an axial load of $1600 \mathrm{kN}$. The two joints were grouted with a modified epoxy resin in the seam. It is evident that cracks appeared earlier in the $95 \mathrm{~mm}$ joint and developed more quickly than in the $195 \mathrm{~mm}$ joint. Additionally, the bending 


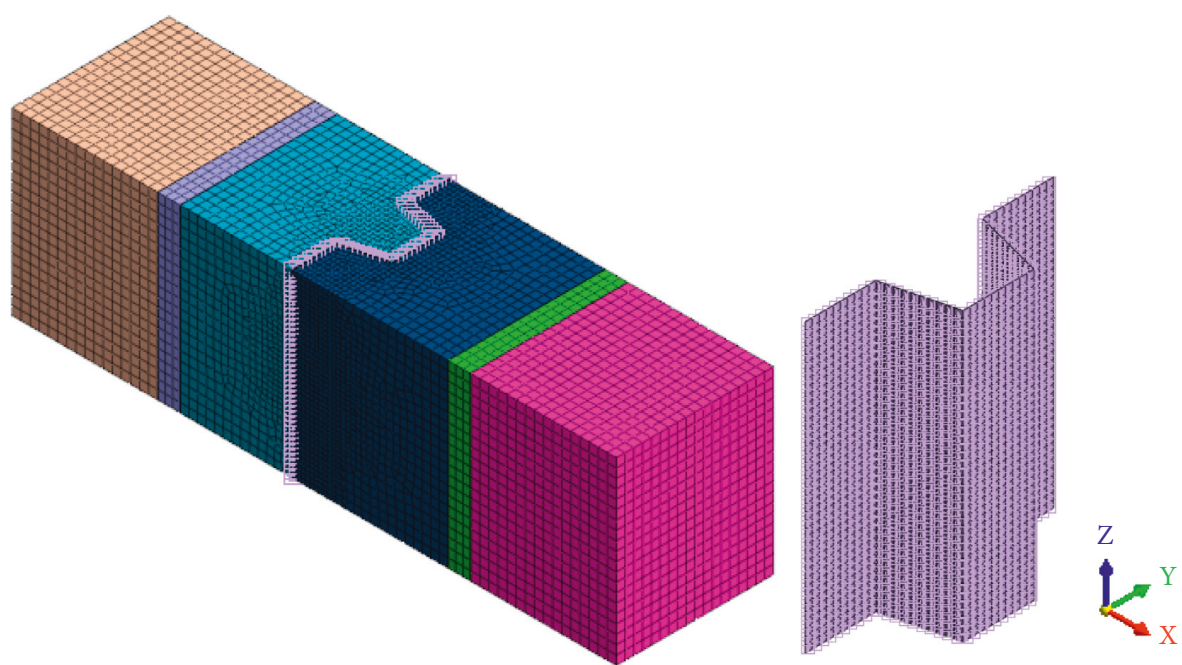

Figure 9: Numerical model of long tenon without grout (same as experimental specimen).

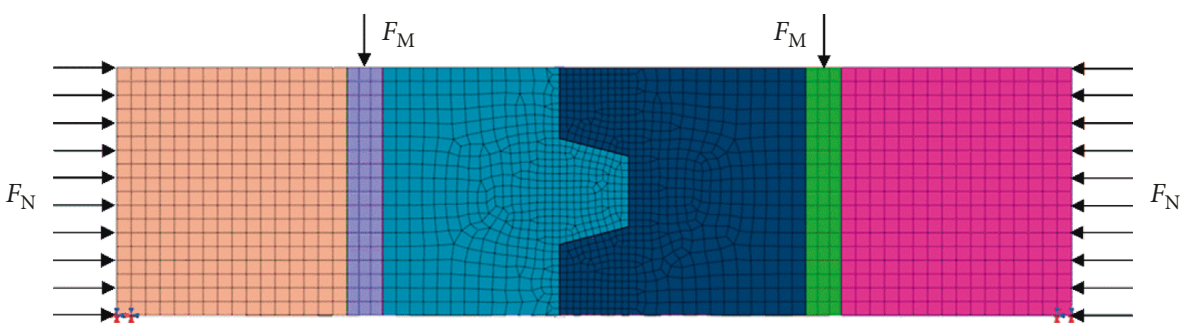

FIGURE 10: Loading and boundary conditions of the numerical model.

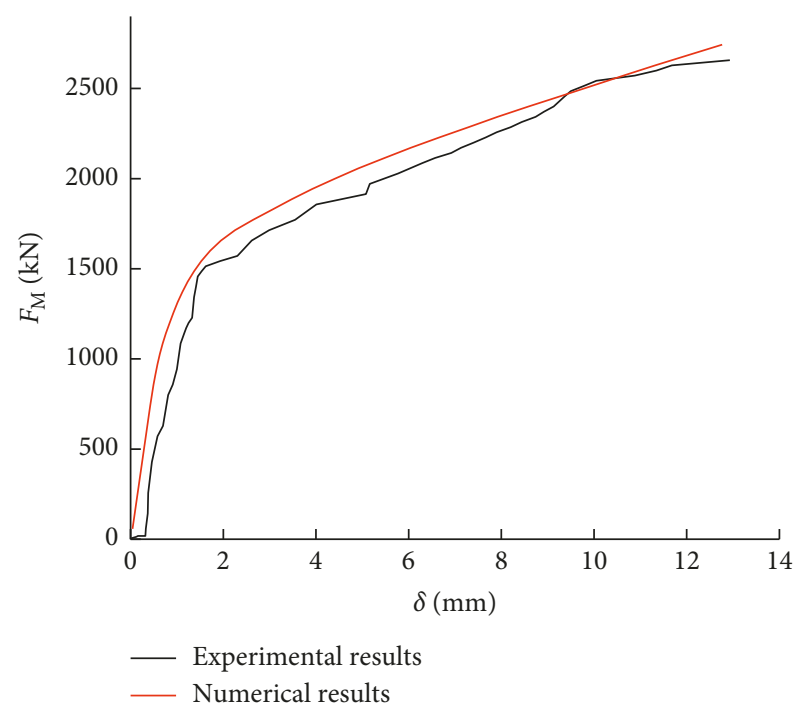

FIGURE 11: Comparison of load-deflection curves of experimental and numerical results.

moment in every key stage of the $195 \mathrm{~mm}$ joint was larger than that in the $95 \mathrm{~mm}$ joint, as can be seen in Figure 17(b). This trend is also present when using other grouting materials under other axial loads, as can be seen in Figures 17(a) and $17(\mathrm{c})$. This is because the $195 \mathrm{~mm}$ joint has a longer embedded length than the $95 \mathrm{~mm}$ joint, making it stronger. It can also be seen from Figures 17(a) and 17(b) that the

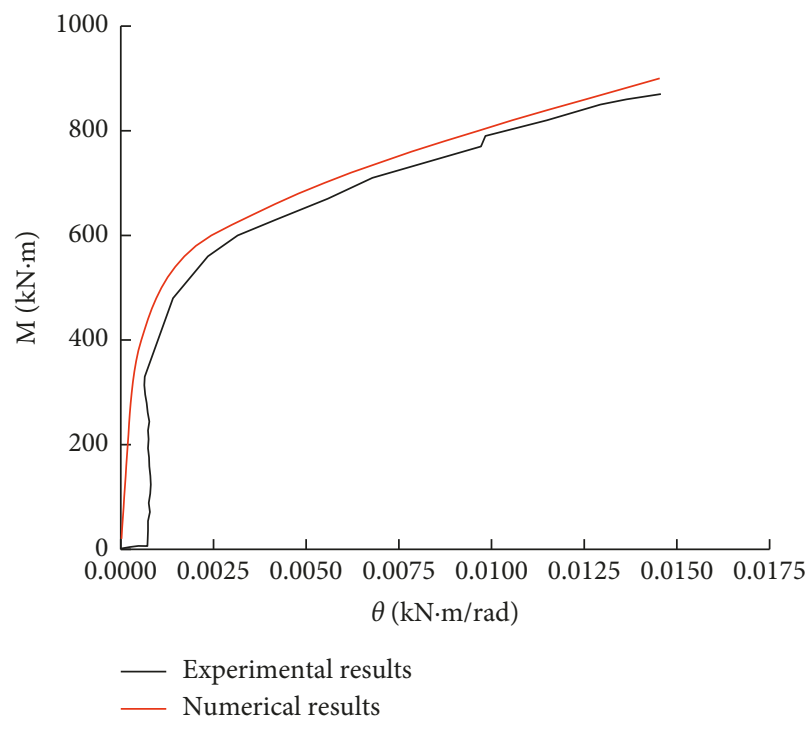

FIGURE 12: Comparison of moment-rotation curves of experimental and numerical results.

larger the axial load, the larger the difference in performance between the $195 \mathrm{~mm}$ and $95 \mathrm{~mm}$ joints.

As can be observed in Figure 18, a longer embedded length helps to restrict the opening of the joint, as indicated by a lower deflection under the same applied moment. Indeed, joint deformation initially remains very small before 


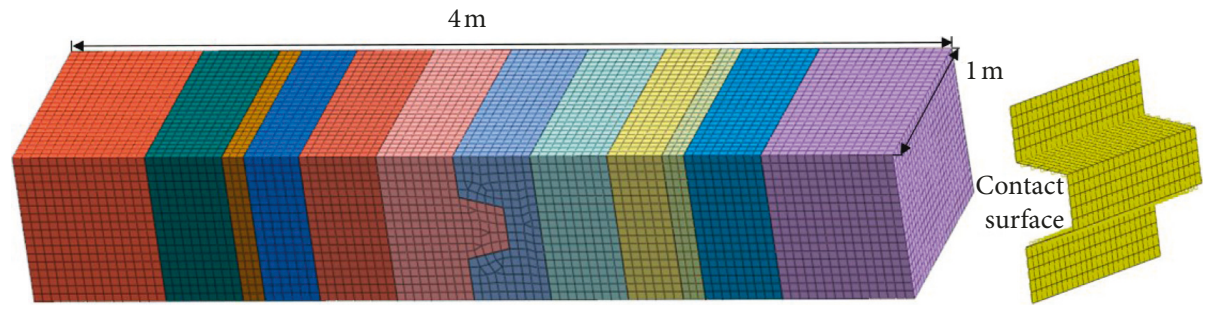

FIGURE 13: Calculation model for influence analysis of different geometrical parameters.

TABLE 1: Numerical simulation cases.

\begin{tabular}{lccc}
\hline Axial load $(\mathrm{kN})$ & Joint parameters & Variable parameters & Fixed parameters \\
\hline 500, & Dip angle & $\alpha=70^{\circ}, 76^{\circ}, 80^{\circ}, 90^{\circ}$ & $l=195 \mathrm{~mm}, w=300 \mathrm{~mm}$, and $i=0 \mathrm{~mm}$ \\
1000, & Width & $w=200 \mathrm{~mm}, 250 \mathrm{~mm}, 300 \mathrm{~mm}, 350 \mathrm{~mm}$, & $\alpha=76^{\circ}, l=195 \mathrm{~mm}$, and $i=0 \mathrm{~mm}$ \\
1600, & $400 \mathrm{~mm}$, and $450 \mathrm{~mm}$ & $\alpha=90^{\circ}, w=300 \mathrm{~mm}$, and $I=0 \mathrm{~mm}$ \\
2000 & Length & $l=95 \mathrm{~mm}, 145 \mathrm{~mm}, 195 \mathrm{~mm}, 245 \mathrm{~mm}$, & $295 \mathrm{~mm}$, and $345 \mathrm{~mm}$ \\
2500, & Indentation (ratio) & $i=0 \mathrm{~mm}, 150 \mathrm{~mm}(30 \%), 200 \mathrm{~mm}(40 \%)$, & $\alpha=76^{\circ}, l=195 \mathrm{~mm}$, and $w=300 \mathrm{~mm}$ \\
3000, & and $250 \mathrm{~mm}(50 \%)$ & \\
4000 & &
\end{tabular}

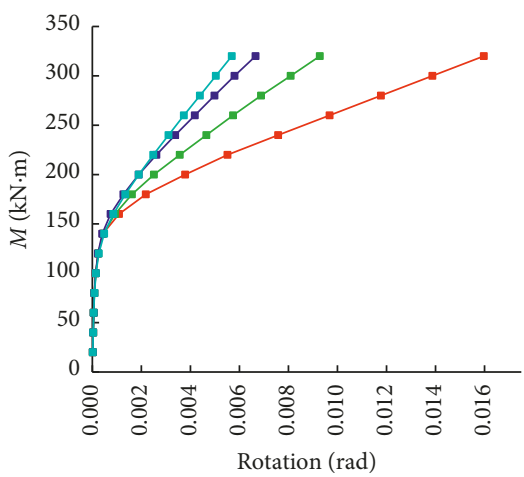

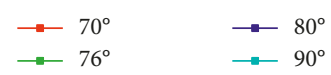

(a)

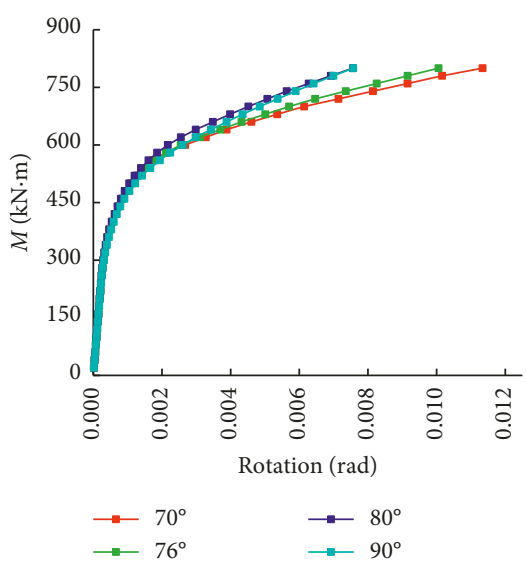

(d)

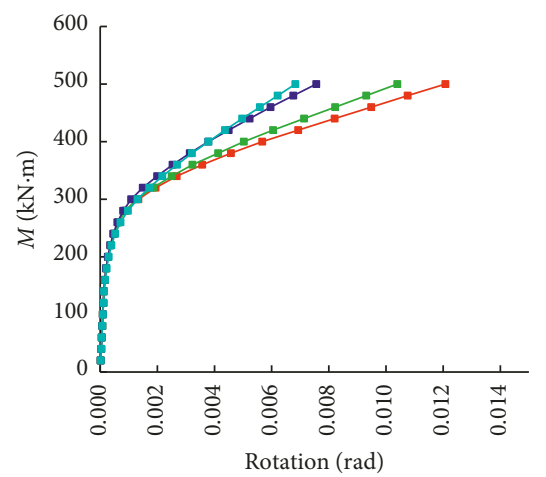

$\rightarrow 70^{\circ}$

$\rightarrow 80^{\circ}$

(b)

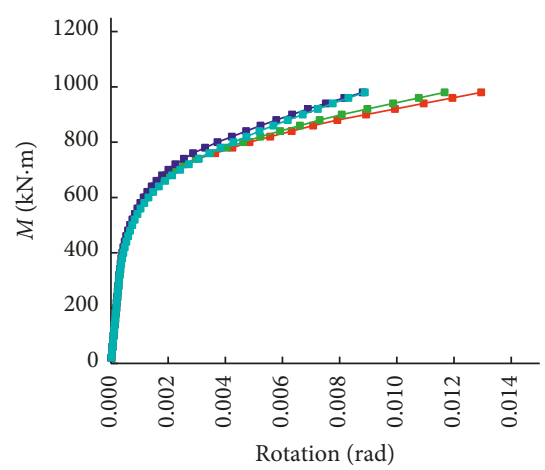

$\because 70^{\circ}$

$\rightarrow \quad 80^{\circ}$

(e)

FIgURE 14: Continued.

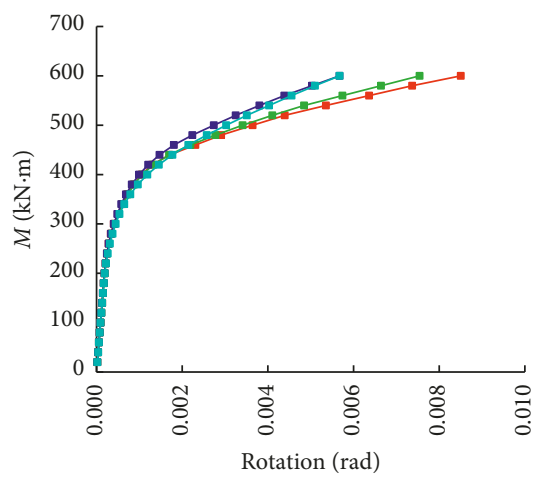

$\begin{array}{ll}\rightarrow 70^{\circ} & \rightarrow \\ \rightarrow-76^{\circ} & \rightarrow-90^{\circ}\end{array}$

(c)

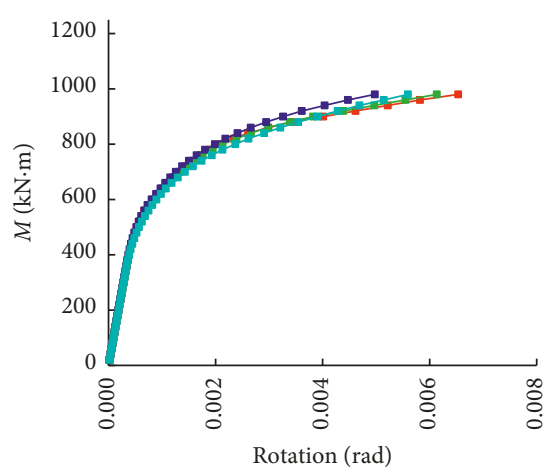

$\begin{array}{ll}\rightarrow & 70^{\circ} \\ \rightarrow-76^{\circ} & \rightarrow-80^{\circ}\end{array}$

(f) 


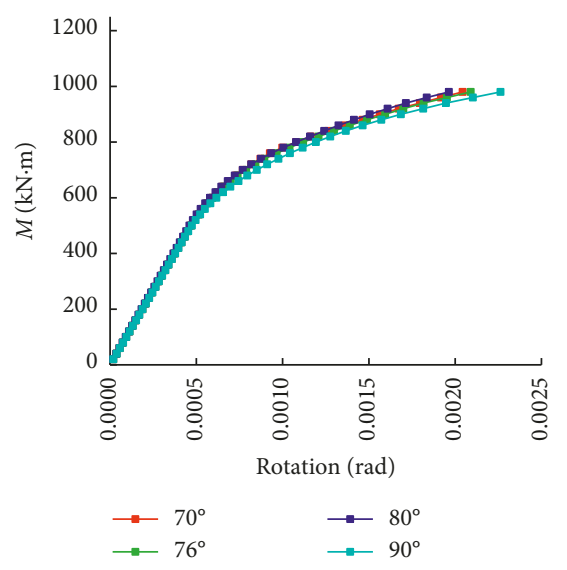

(g)

Figure 14: Bending moment-rotation curves for different tenon dip angles under axial loads of (a) $500 \mathrm{kN}$, (b) $1000 \mathrm{kN}$, (c) $1500 \mathrm{kN}$, (d) $2000 \mathrm{kN}$, (e) $2500 \mathrm{kN}$, (f) $3000 \mathrm{kN}$, and (g) $4000 \mathrm{kN}$.

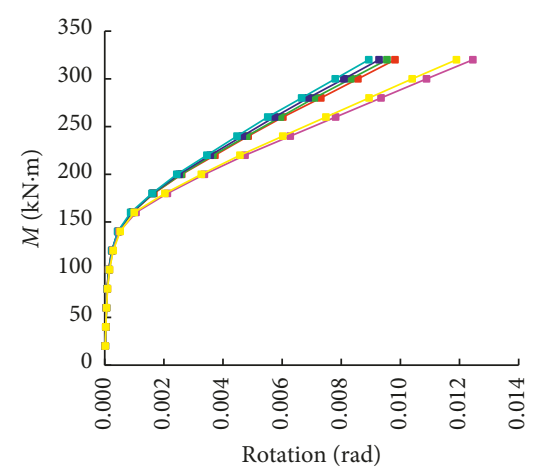

$\rightarrow-200$

$\rightarrow 250$

$\rightarrow-300$

$-\quad 350$

$-400$

(a)

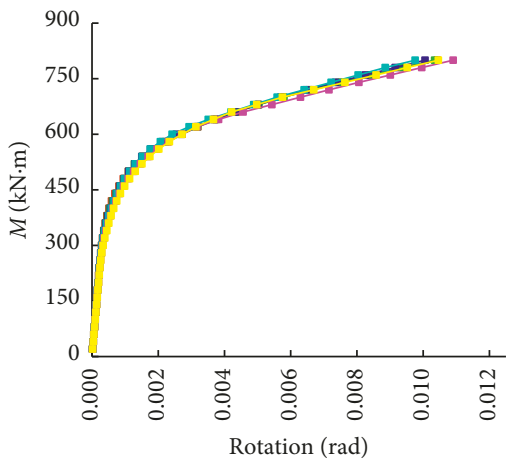

$$
\begin{array}{ll}
\rightarrow-200 & \rightarrow-350 \\
\rightarrow-250 & \rightarrow-400 \\
\rightarrow-300 & -
\end{array}
$$

(d)
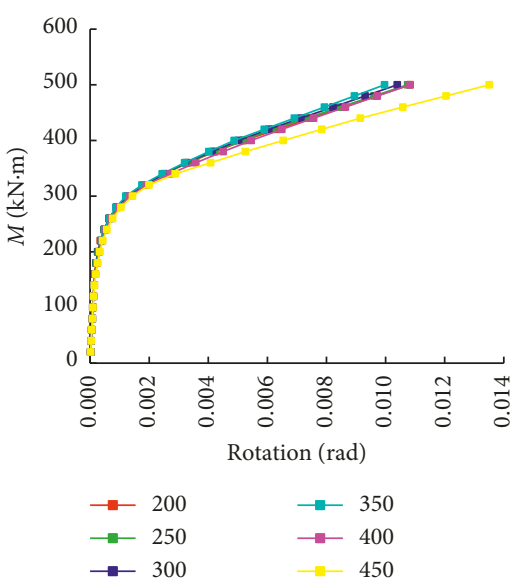

(b)

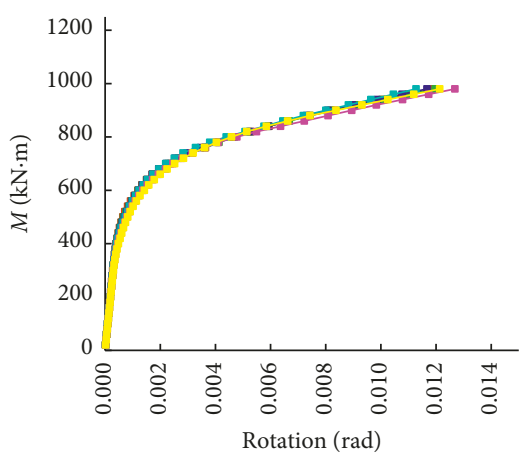

$\begin{array}{ll}\rightarrow-200 & \rightarrow-350 \\ --250 & \rightarrow-400 \\ -300 & -450\end{array}$

(e)

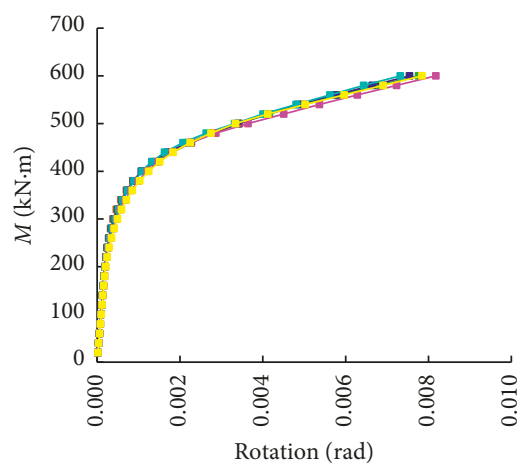

$\rightarrow-200$

$\rightarrow-350$

$-400$

(c)

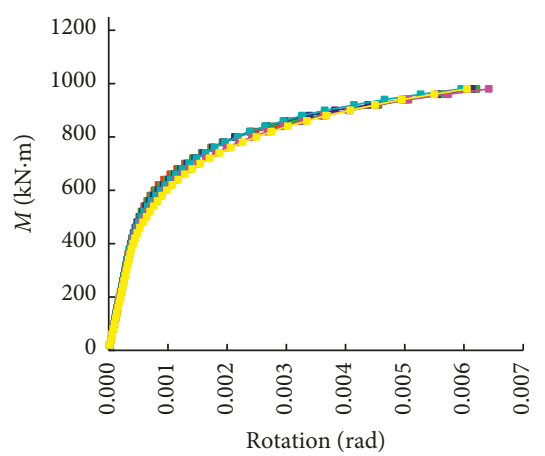

$$
\begin{aligned}
& \rightarrow 200 \quad-350 \\
& \rightarrow-250 \\
& \longrightarrow \quad 400
\end{aligned}
$$

(f)

Figure 15: Continued. 


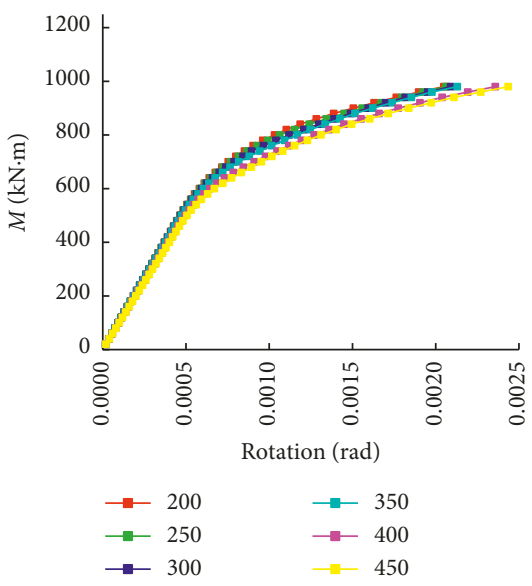

(g)

FiguRE 15: Bending moment-rotation curves for different tenon widths under axial loads of (a) $500 \mathrm{kN}$, (b) $1000 \mathrm{kN}$, (c) $1500 \mathrm{kN}$, (d) $2000 \mathrm{kN}$, (e) $2500 \mathrm{kN}$, (f) $3000 \mathrm{kN}$, and (g) $4000 \mathrm{kN}$.

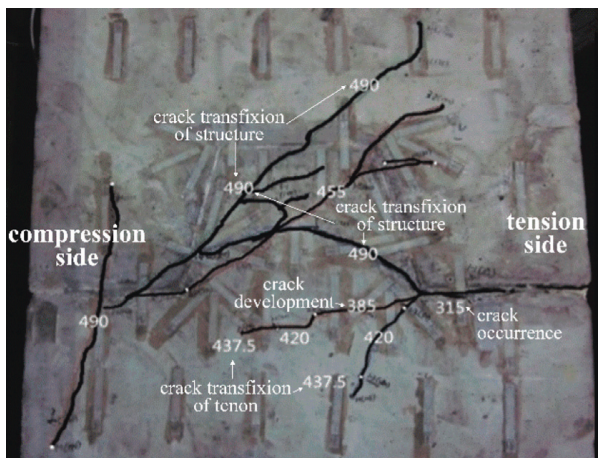

(a)

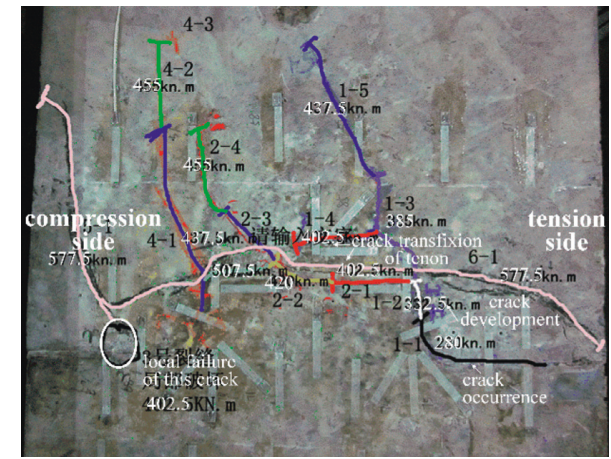

(b)

FiguRE 16: Crack development with loading for different joint lengths. (a) $195 \mathrm{~mm}$, (b) $95 \mathrm{~mm}$.

quickly increasing at the same bending moment as that of the crack transfixion of the tenon (Figure 16). Furthermore, the moment-deformation inflection point of the $195 \mathrm{~mm}$ joint is larger than that of the $95 \mathrm{~mm}$ joint, and the maximum carrying capacity and deformation resistance of the $195 \mathrm{~mm}$ joint are clearly higher than those of the $95 \mathrm{~mm}$ joint.

Figure 19 shows the simulated relationship between the bending moment $M$ and rotation angle $\theta$ for different tenon lengths without grouting under various axial loads. At the beginning of loading, the length clearly has little effect on the $M-\theta$ relationship curves under any axial load. With increased loading, all the curves enter a nonlinear section at nearly the same bending moment, with an overlapping range in the beginning of this stage that grows larger as the axial load increases. Once in the nonlinear section of the curves, the longer tenons begin to exhibit better flexural rigidity. The effect of using a longer tenon is most obvious when the axial load is small. As shown in Figure 19(a), the flexural rigidities at tenon lengths of $95 \mathrm{~mm}$ and $145 \mathrm{~mm}$ are smaller than those at other lengths under an axial load of $500 \mathrm{kN}$. For tenon lengths greater than $195 \mathrm{~mm}$, there is little difference in flexural rigidity; that is, the benefit of using a longer tenon declines as the axial load increases. When the axial load is $4000 \mathrm{kN}$, the flexural rigidity of a $345 \mathrm{~mm}$ long tenon is actually slightly lower than that of a $245 \mathrm{~mm}$ long tenon. Therefore, increasing the length of the tenon does not significantly improve flexural rigidly once the tenon length is sufficiently long. When the axial load is small, the rotations of the shorter joints are high under the same bending moment in later periods of loading. However, this difference decreases with increased axial load. Though all of these findings were obtained from the model with a dip angle of $90^{\circ}$, by consulting the results of tests using different dip angles, a dip angle $90^{\circ}$ has the largest flexural rigidity while the trend of the different dip angles are all the same. Thus, evaluating the model with the $90^{\circ}$ dip angle not only removes the influence of other parameters, but also provides a certain wider representativeness.

In summary, an appropriate increase in the length of the tenon can be beneficial to its flexural rigidity. A tenon length of $195 \mathrm{~mm}$, as used in the joints of the prefabricated structures for building the metro stations evaluated in this study, provides a flexural capacity better than that at tenon lengths of $145 \mathrm{~mm}$ and $95 \mathrm{~mm}$. When the length of the 


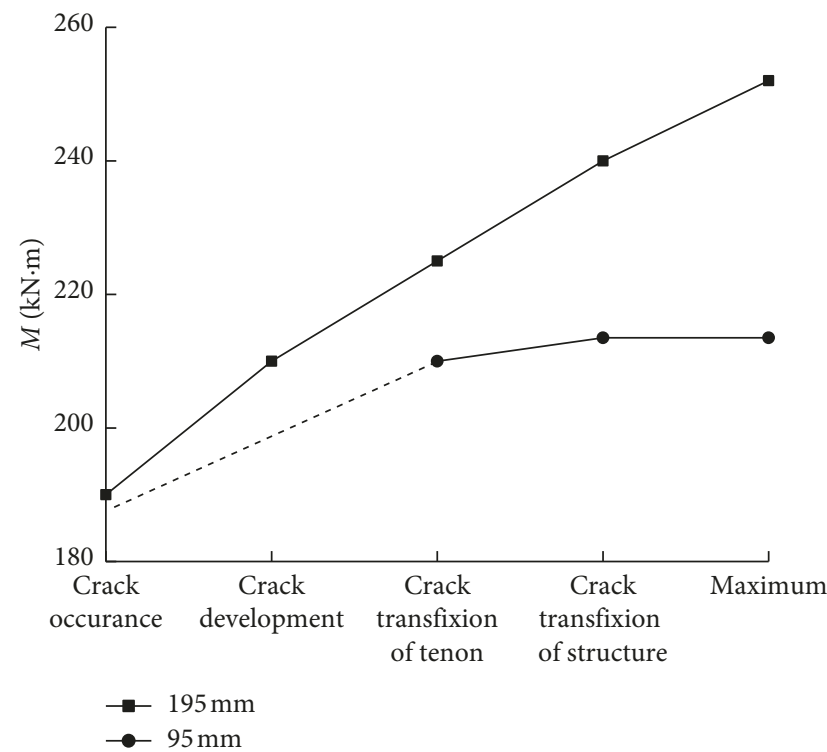

(a)

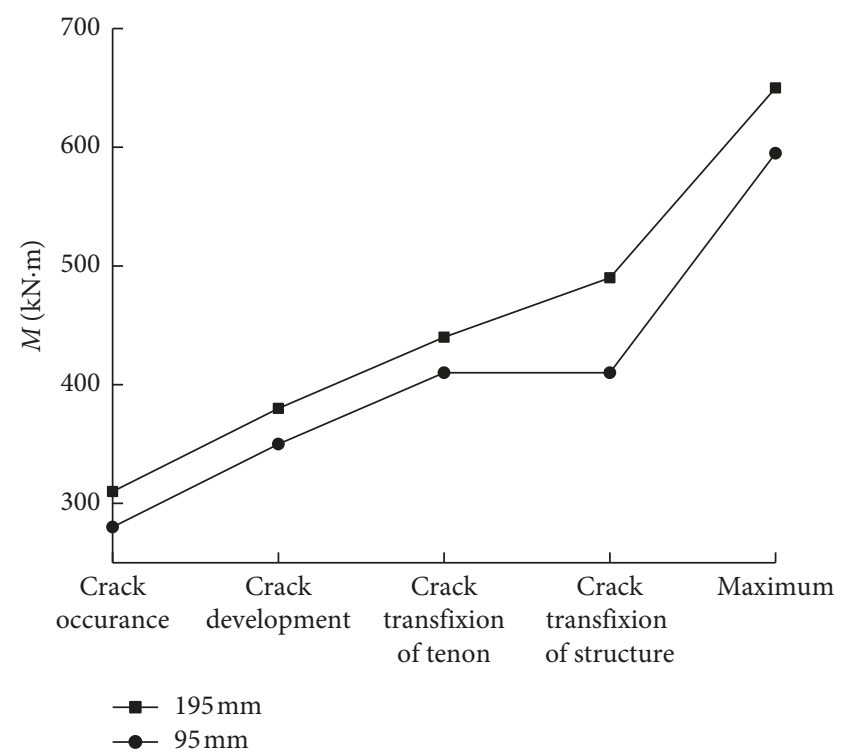

(b)

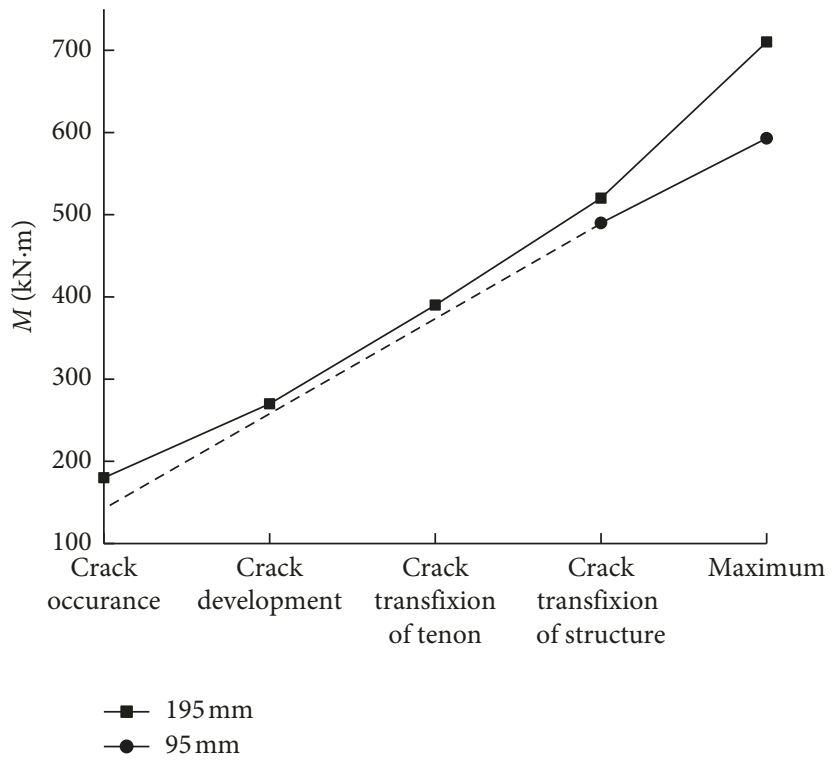

(c)

Figure 17: Key bending moments of joints with different tenon lengths and (a) modified epoxy resin grout at $500 \mathrm{kN}$ axial load, (b) modified epoxy resin grout at $1600 \mathrm{kN}$ axial load, and (c) modified cement-based material at $1600 \mathrm{kN}$ axial load.

tenon is sufficiently long $(195 \mathrm{~mm}, 245 \mathrm{~mm}, 295 \mathrm{~mm}$, and $345 \mathrm{~mm}$ ), the positive effects of using a longer tenon are not obvious. Therefore, actual loading conditions should be taken into consideration when choosing the tenon length as an excessively long tenon may lead to bending failure.

6.4. Influence of Different Indentations. Figure 20 presents the relationship between the bending moment $M$ and rotation angle $\theta$ for different indentations under various axial loads. In the beginning, all curves are nearly coincident, indicating that the indentation has little effect on the joint behavior under different axial loads at this stage.
With increased loading, all curves enter the bending section under nearly the same bending moment, with an overlapping range in the beginning of this stage that grows larger as the axial load increases. The flexural rigidity for a $0 \mathrm{~mm}$ indentation is lower than that for other indentations under all axial loads. It is clear then that mortising the tenon on two additional sides (an indentation $\neq 0$ ) increases the friction between the side faces of the tenon and mortise, improving the moment capacity of the joint. This phenomenon is more obvious under small axial loads as the advantage of providing an indentation on these sides decreases as the axial load increases. Even when the axial load is $4000 \mathrm{kN}$, there is very little difference in the $M-\theta$ relationship curves for all indentation cases. A longer 


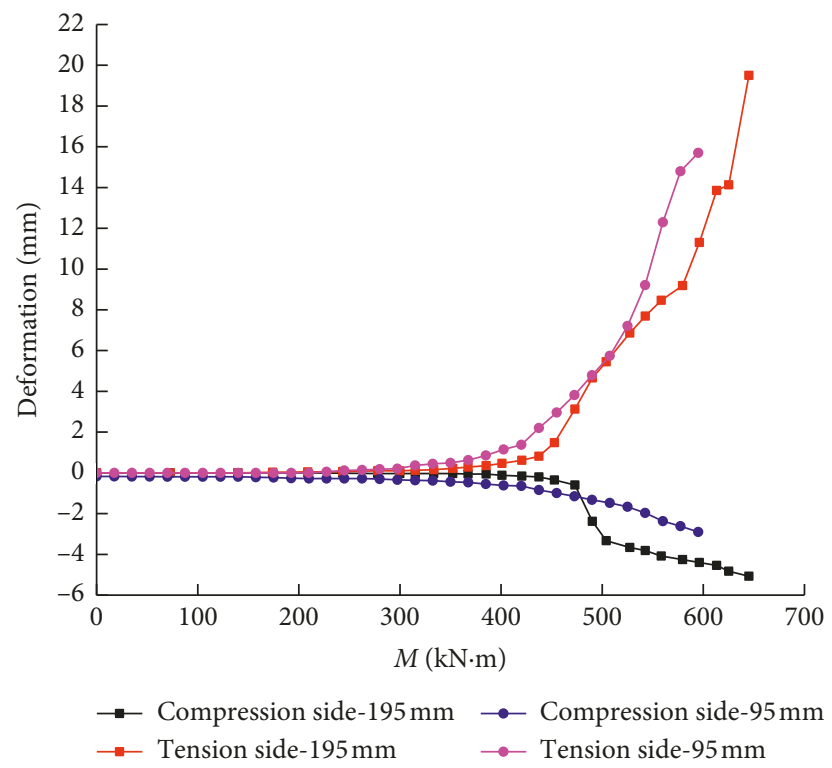

Figure 18: Comparison of experimentally observed joint deformations for different tenon lengths.

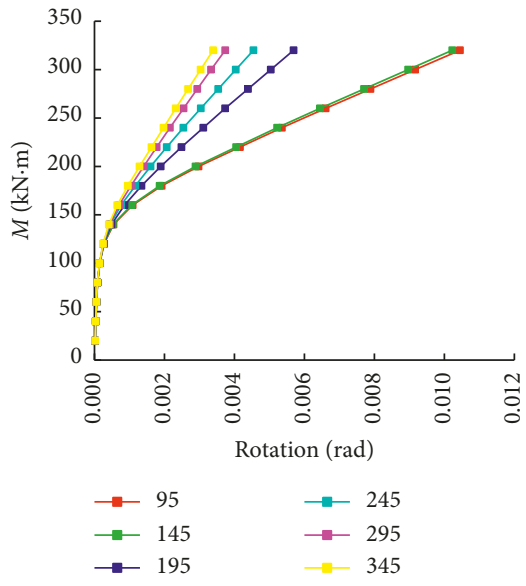

(a)

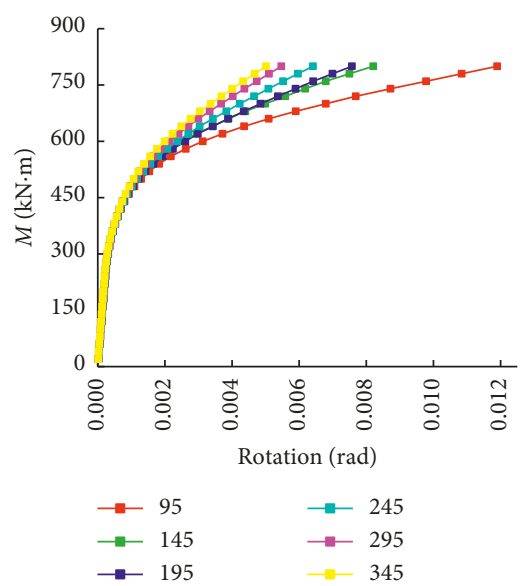

(d)

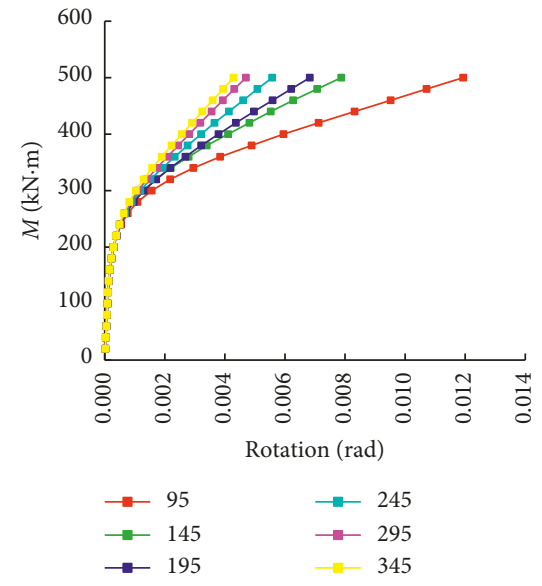

(b)

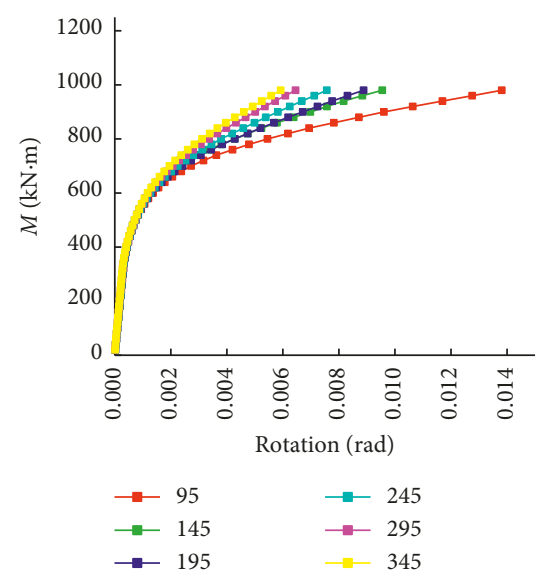

(e)

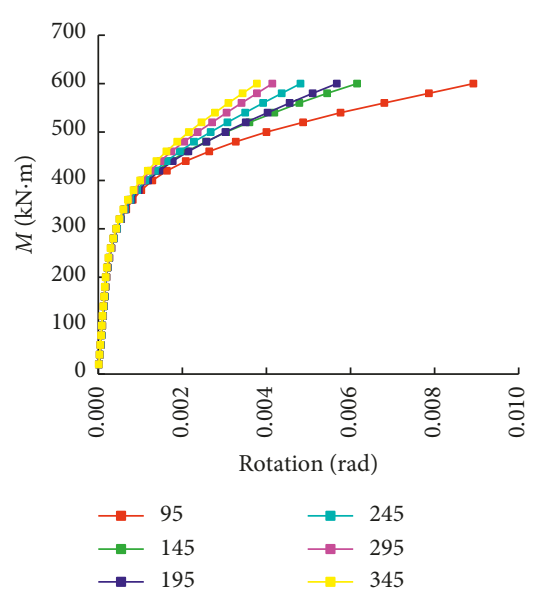

(c)

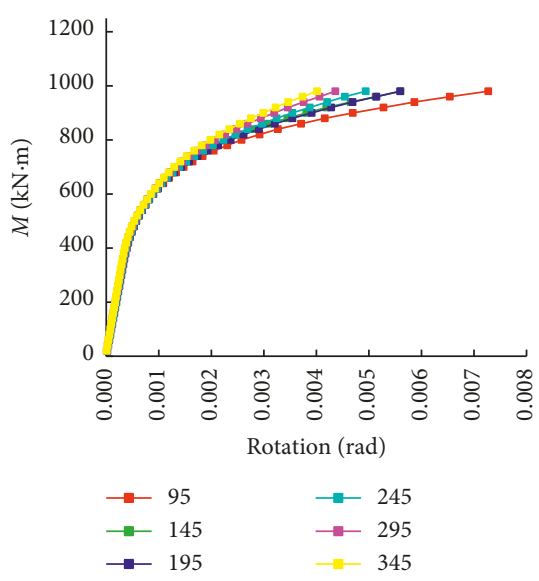

(f)

Figure 19: Continued. 


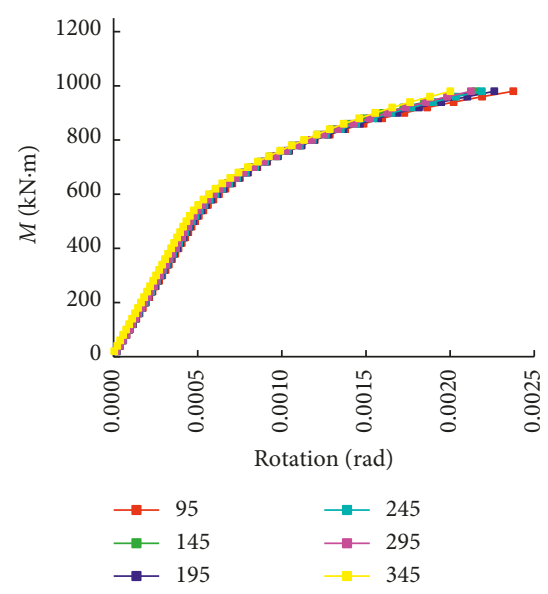

(g)

FIGURE 19: Bending moment-rotation curves for different tenon lengths under axial loads of (a) $500 \mathrm{kN}$, (b) $1000 \mathrm{kN}$, (c) $1500 \mathrm{kN}$, (d) $2000 \mathrm{kN}$, (e) $2500 \mathrm{kN}$, (f) $3000 \mathrm{kN}$, and (g) $4000 \mathrm{kN}$.

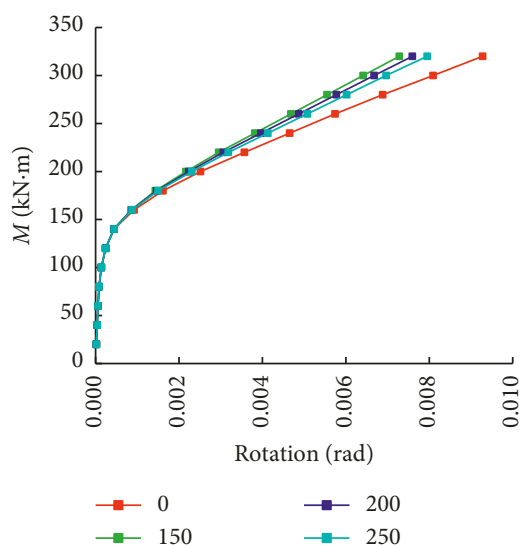

(a)

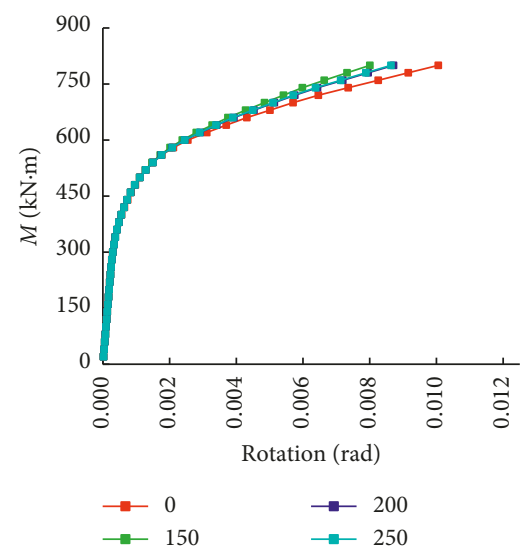

(d)

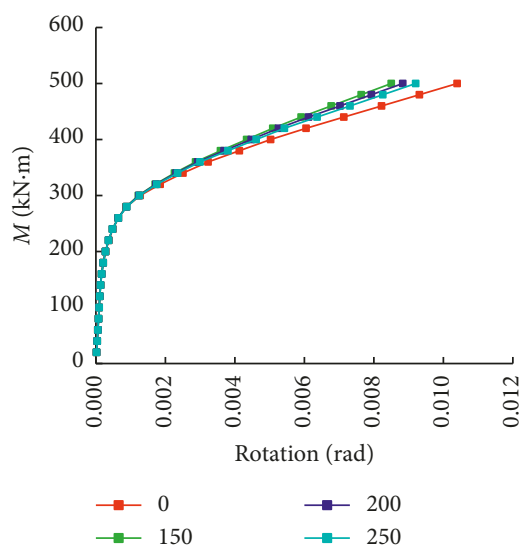

(b)

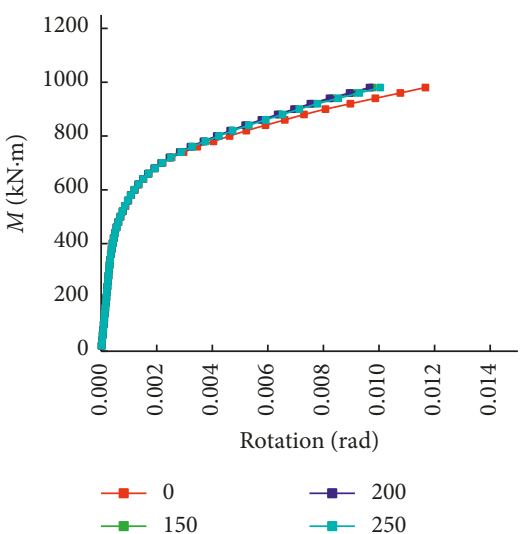

(e)

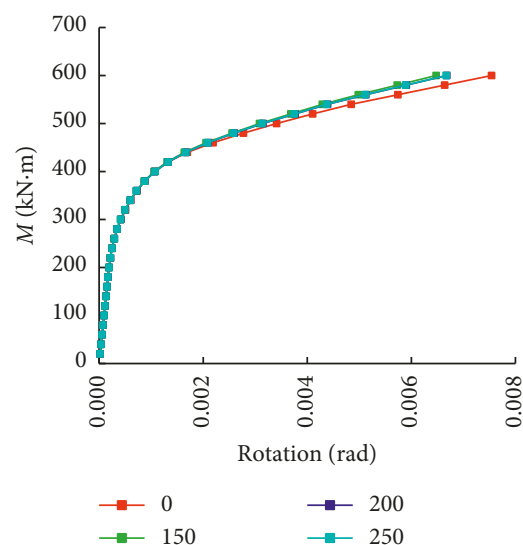

(c)

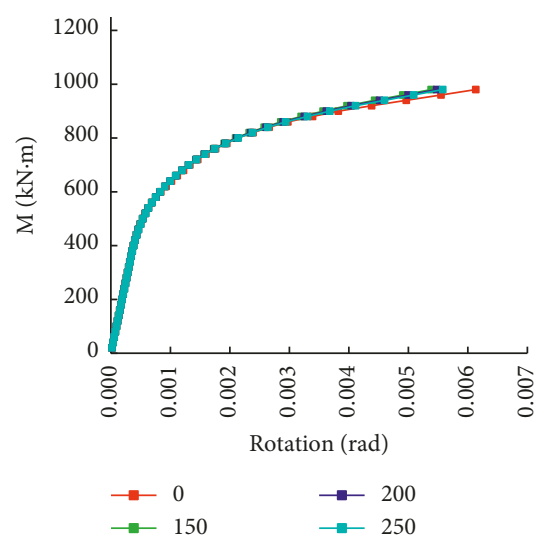

(f)

Figure 20: Continued. 


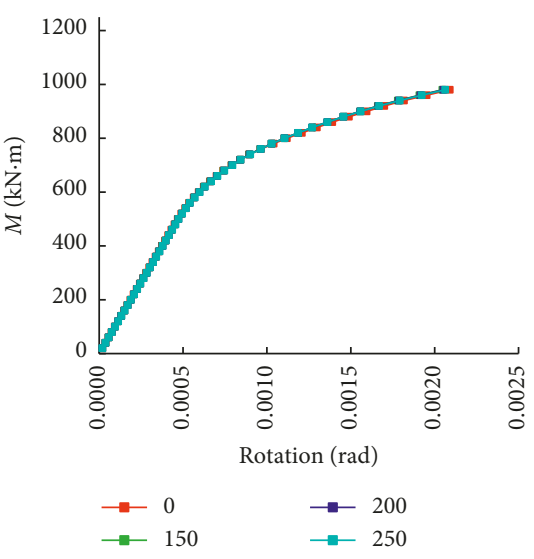

(g)

Figure 20: Bending moment-rotation curves of different tenon indentations under axial loads of (a) $500 \mathrm{kN}$, (b) $1000 \mathrm{kN}$, (c) $1500 \mathrm{kN}$, (d) $2000 \mathrm{kN}$, (e) $2500 \mathrm{kN}$, (f) $3000 \mathrm{kN}$, and (g) $4000 \mathrm{kN}$.

indentation does not contribute to increased flexural capacity. It can be observed in Figure 20 that the flexural capacities of the indentations can be ranked $150 \mathrm{~mm}>$ $200 \mathrm{~mm}>250 \mathrm{~mm}$ under axial loads of $500 \mathrm{kN}$ and $1000 \mathrm{kN}$, but the effect of the indentation is much more obvious at $500 \mathrm{kN}$. An indentation of $150 \mathrm{~mm}$ exhibits the best performance under all axial loads, especially those less than $3000 \mathrm{kN}$. When the axial load is greater than $3000 \mathrm{kN}$, the effects of the different indentations are not clear.

Based on the above findings, reasonable indentation can be stated to ensure effective mortising of the tenon, which is beneficial for the flexural capacity of the joint, especially under a small axial load. However, a larger indentation does not guarantee better performance of the joint. For the $1 \mathrm{~m}$ wide prefabricated element evaluated in the numerical model, an indentation rate of $30 \%$ provides the best performance.

\section{Conclusion}

This study analyzed the influence of geometric parameters on the behavior of mortise and tenon joints used in prefabricated structures installed underground. To evaluate the effect of a wide range of parameters on the performance of the joints, a finite element model simulating suitable contact was constructed based on the results of experimental joint testing. The following conclusions can be drawn from the findings:

(a) Increasing the dip angle of the tenon can improve the flexural rigidity of the joint, but the effect is relatively small compared to that of other parameters. When the axial load is sufficiently high $(>4000 \mathrm{kN})$, the stress concentration at the top of a tenon with a $90^{\circ}$ dip angle increases significantly. Therefore, the flexural capacity of the joint is reduced.

(b) When the axial load is small, increasing the width of the tenon is beneficial to the flexural capacity of the joint for relatively small widths (200-350 mm); increasing the tenon width does not significantly improve the flexural capacity of the joint at relatively high widths (400-450 $\mathrm{mm}$ ).

(c) Increasing the length of the tenon helps to enhance the flexural performance of the joint. However, this advantage is not obvious when the length of the tenon is relatively long $(195 \mathrm{~mm}, 245 \mathrm{~mm}, 295 \mathrm{~mm}$, and $345 \mathrm{~mm}$ ).

(d) Proper indentation of the mortise and tenon joint improves its flexural capacity under a small axial load. However, indentation changes are not beneficial when the axial load is high $(>3000 \mathrm{kN})$. For the $1 \mathrm{~m}$ wide prefabricated element evaluated in the numerical model, an indentation rate of $30 \%$ is recommended for small axial loads.

In summary, the different geometrical parameters (dip angles, widths, lengths, and indentations) of the mortise and tenon joints used in prefabricated structures should be selected after considering the various axial loads, loading conditions, and relationships between parameters in order to ensure environmentally friendly, readily assembled prefabricated structures for constructing underground structures such as the stations installed in Line 2 of the Changchun Metro.

\section{Data Availability}

The data used to support the findings of this study are available from the corresponding author upon request.

\section{Conflicts of Interest}

The authors declare no conflicts of interest.

\section{Authors' Contributions}

Xiuren Yang supervised the project and developed the concept and methodologies with Zhongheng Shi. Fang Lin performed the experimental and numerical studies. 


\section{Acknowledgments}

This research was funded by the National Key S\&T Special Projects (grant number 2017YFB1201104).

\section{References}

[1] X. R. Yang and M. Q. Huang, "Research strategies on new prefabricated technology of underground subway station," Urban Rapid Rail Transit, vol. 31, no. 1, pp. 78-85, 2018.

[2] A. Akin and R. Sezer, "A study on strengthening of reinforced concrete frames using precast concrete panels," KSCE Journal of Civil Engineering, vol. 20, no. 6, pp. 2439-2446, 2016.

[3] R. J. Frosch, W. Li, J. O. Jirsa, and M. E. Kreger, "Retrofit of non-ductile moment-resisting frames using precast infill wall panels," Earthquake Spectra, vol. 12, no. 4, pp. 741-760, 1996.

[4] D. A. Steinhardt and K. Manley, "Adoption of prefabricated housing-the role of country context," Sustainable Cities and Society, vol. 22, pp. 126-135, 2016.

[5] S. M. Senel and M. Palanci, "Structural aspects and seismic performance of 1-story precast buildings in Turkey," Journal of Performance of Constructed Facilities, vol. 27, no. 4, pp. 437-449, 2011.

[6] C. Casotto, V. Silva, H. Crowley, R. Nascimbene, and R. Pinho, "Seismic fragility of Italian RC precast industrial structures," Engineering Structures, vol. 94, pp. 122-136, 2015.

[7] T. C. Gu, "Development status of prefabricated architecture at home and abroad," Standardization of Engineering Construction, vol. 8, pp. 48-51, 2014.

[8] Chinese Technical Regulations, Technical Specification for Fabricated Concrete Structures: JGJ1-2014, China Construction Industry Press, Beijing, China, 2014.

[9] J. H. Liu and X. Y. Hou, "The history of shield tunneling," in Shield Tunneling, China Railway Press, Beijing, China, 1991.

[10] K. Beilasov, Q. H. Qian, and C. Z. Qi, The Essence of the Construction of Russian Underground Railway, China Railway Press, Beijing, China, 2012.

[11] S. Teachavorasinskun and T. Chub-Uppakarn, "Influence of segmental joints on tunnel lining," Tunneling and Underground Space Technology, vol. 25, no. 4, pp. 490-494, 2010.

[12] B. Tvede-Jensen, M. Faurschou, and T. Kasper, "A modelling approach for joint rotations of segmental concrete tunnel linings," Tunnelling and Underground Space Technology, vol. 67, pp. 61-67, 2017.

[13] Japanese Prefabricated Building Association, Pandect of Prefabricated Buildings, China Architecture \& Building Press, Beijing, China, 2012. 


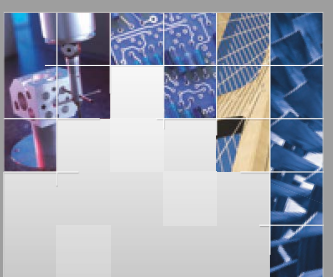

\section{Enfincering}
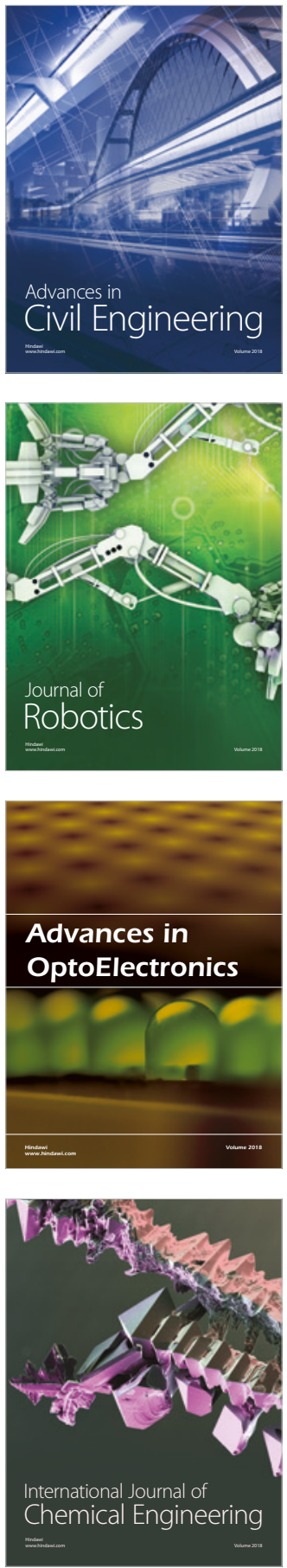

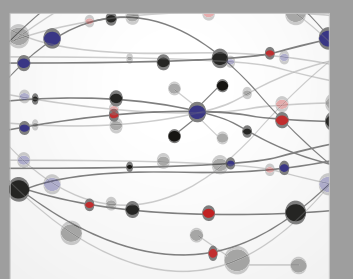

\section{Rotating \\ Machinery}

The Scientific World Journal

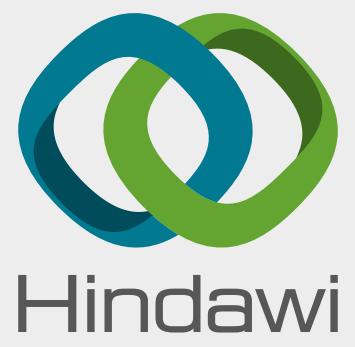

Submit your manuscripts at

www.hindawi.com
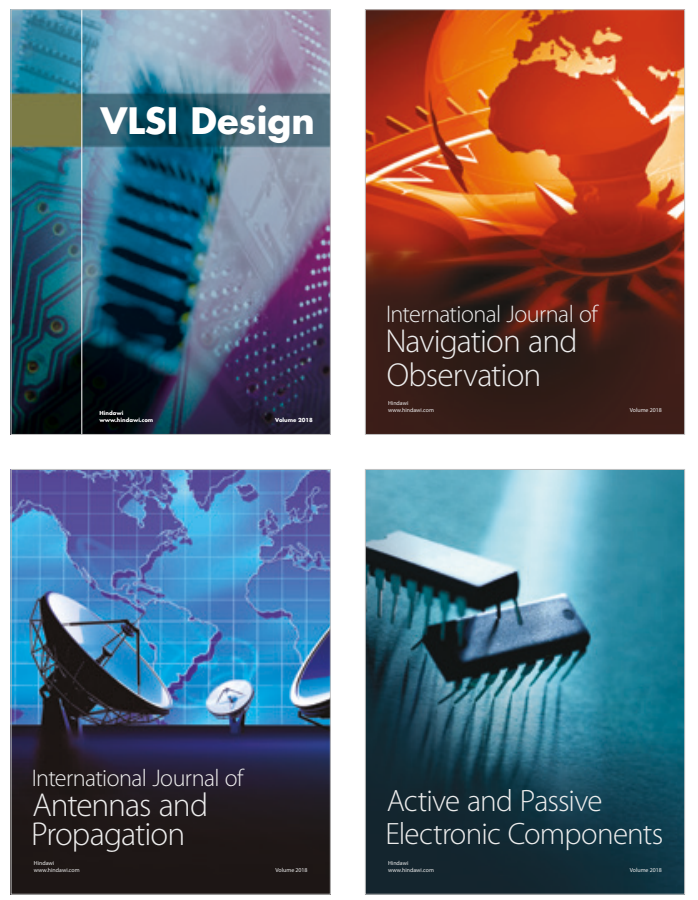
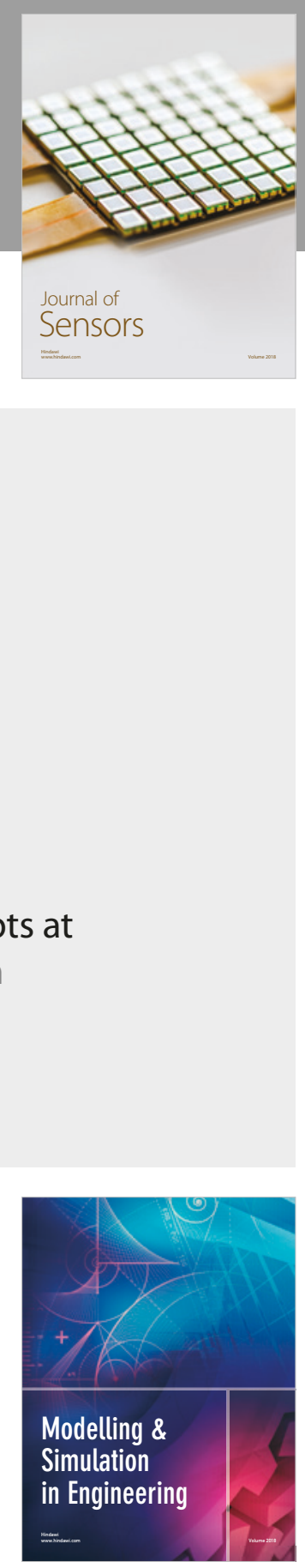

\section{Advances \\ Multimedia}
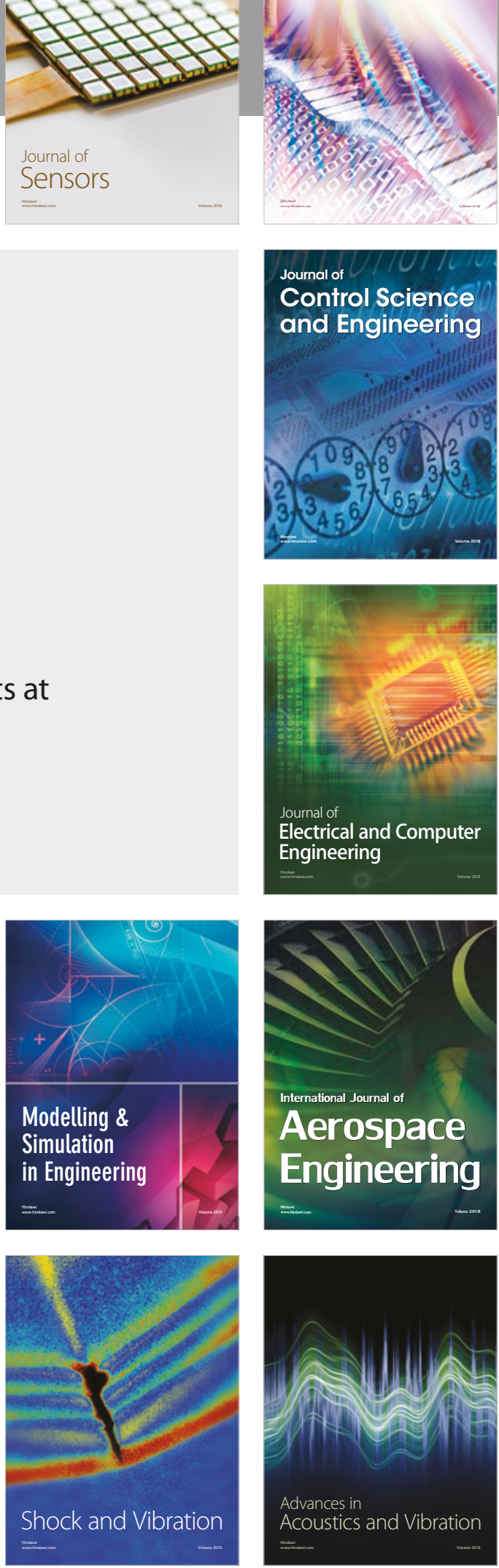